Chirurgia (2019) 114: 686-692

No. 6, November - December

Copyright $\odot$ Celsius

http://dx.doi.org/10.21614/chirurgia.114.6.686

\title{
Esophago-Gastric Cancer after One Anastomosis Gastric Bypass (OAGB)
}

\section{Mira Runkel', Norbert Runkel ${ }^{2}$}

'Department of General and Visceral Surgery, University of Freiburg, Germany

${ }^{2}$ Department of Bariatric and Metabolic Surgery, Sana-Hospital, Offenbach, Germany

Corresponding author:

Norbert Runkel, MD

Department of Bariatric and

Metabolic Surgery, Sana-Hospital,

63069 Offenbach, Germany

E-mail: Norbert.Runkel@icloud.com

\section{Abbreviations:}

OAGB - One Anastomosis Gastric Bypass: MGB - Mini Gatric Bypass:

AEG - Adenocarcinoma of the EsophagoGastric junction;

RYGB - Roux-en-Y Gastric Bypass;

$S G$ - Sleeve Gastrectomy.

\section{Rezumat \\ Cancerul esogastric după bypass-ul gastric cu o singură anastomoză (OAGB)}

Bypass-ul gastric cu o singură anastomoză - one anastomosis gastric bypass $(O A G B)$ este o tehnică bariatrică care presupune creearea unui rezervor gastric tubular anastomozat larg, terminolateral, la jejun. Este o operație non-complexă, cu o frecvență scăzută a obstrucțiilor intestinale şi o excelentă pierdere în greutate pe termen lung, cu toate acestea, există o teamă de cancerul esofagogastric. Această analiză narativă explorează riscul dezvoltării cancerului după OAGB. Cinci cancere gastrice au fost publicate după minigastric bypass gastric - MGB (o versiune timpurie a OAGB, $n=4)$ şi după OAGB modern $(n=1)$, dintre care patru au apărut în stomacul restant şi unul în rezervorul gastric. Refluxul jejuno-gastric este o condiție normală după OAGB, dar nu există dovezi care să sugereze degenerarea malignă indusă de prezența bilei în stomac. Pe de alta parte, deşi refluxul gastro-esofagian este o cauză clară a metaplaziei şi adenocarcinomului esogastric (AEG), totuşi, refluxul gastro-esofagian este rar, şi au fost raportate doar două cazuri de AEG în literatura de specialitate. Evaluarea gastroscopică postoperatorie trebuie luată în considerare la pacientii cu reflux gastro-esofagian şi / sau hernie hiatală. Când refluxul devine simptomatic, ar trebui recomandată conversia OAGB la bypass gastric pe ansa a la Roux-en-Y.

Cuvinte cheie: bypass gastric, OAGB, MGB, cancer gastric, cancer esofagian, reflux biliar 


\begin{abstract}
One Anastomosis Gastric Bypass (OAGB) is a bariatric technique that combines a long tube-like gastric conduit with a wide end-to-side gastro-jejunostomy. It is a non-complex operation with a low frequency of intestinal obstructions and an excellent long-term weight loss, however, there is a fear of esophagogastric cancer. This narrative review explores the risk of cancer development after OAGB. Five gastric cancers were published after loop gastric bypass (an early version of OAGB, $\mathrm{n}=4)$ and after modern OAGB $(\mathrm{n}=1)$, four of which occurred in the remnant stomach and one in the gastric stump. Jejuno-gastric reflux is normal after OAGB, but there is little or no evidence to suggest bile-induced malignant degeneration in the stomach. On the contrary, gastro-esophageal reflux is a clear cause of metaplasia and AEG, although gastro-esophageal reflux is rare after OAGB with only two cases of AEG in the literature. Postoperative gastroscopic surveillance should be considered in patients with gastro-esophageal reflux and/or hiatal hernia. When reflux becomes symptomatic, diversion of the OAGB into a Roux-en-Y construction should be recommended.
\end{abstract}

Key words: One Anastomosis Gastric Bypass, OAGB, MGB, bariatric, gastric cancer, esophageal cancer, bile reflux

\section{Introduction}

One Anastomosis Gastric Bypass (OAGB) is a bariatric surgical technique that combines a long tube-like gastric conduit with a wide end-to-side gastro-(loop)jejunostomy. OAGB was devised by R. Rutledge in 1997 and came a long way from its first publication in 2001 (1) to become consented as a mainstream surgical option (2). It was recently added to the list of standard procedures by the International Federation for the Surgery of Obesity and Metabolic Disorders (IFSO). Various modifications carry different names: Mini Gastric Bypass (MGB); Omega Loop Gastric Bypass (OLGB), Single Anastomosis Gastric Bypass (SAGB). The abbreviations OAGBMGB and MGB-OAGB are also found in the published literature but OAGB is the preferred name by IFSO and thus it is used in this paper.

OAGB leads to sustained weight loss with high remission rates of metabolic comorbidities. A recently published prospective, multicentre, randomised non-inferiority trial from France (YOMEGA) compared the outcomes of OAGB versus standard Roux-en-Y gastric bypass (RYGB) (3). RYGB consisted of a $150 \mathrm{~cm}$ alimentary limb and a $50 \mathrm{~cm}$ biliary limb and OAGB of a single gastrojejunal anastomosis with a $200 \mathrm{~cm}$ biliopancreatic limb. The primary endpoint was weight loss at 2 years.
OAGB ( $\mathrm{n}=117$ ) was not inferior to RYGB $(\mathrm{n}=117)$ regarding excess BMI weight loss $(-87.9 \pm 23.1 \%$ vs. $-85.8 \pm 23.1 \%)$ and remission of related comorbidity but diarrhoea, steatorrhoea and nutritional adverse effects $(21.4 \%$ vs. 0 ; $\mathrm{p}=0.0034$ ) were more frequent in the OAGB group. Another prospective randomized trial from Spain compared OAGB versus sleeve gastrectomy (SG) versus RYGB with 200 patients in each group (4). Five years after surgery, BMI after SG was $30.8 \pm 2.2 \mathrm{~kg} / \mathrm{m}^{2}$, after RYGB $29.9 \pm 2.3 \mathrm{~kg} / \mathrm{m}^{2}$ and after OAGB $25.1 \pm 1.8 \mathrm{~kg} / \mathrm{m}^{2}(\mathrm{p}<0.001)$. Excessive weight loss (\%) was significantly higher after OAGB $(97.9 \pm 7)$ compared to SG $(76.3 \pm 6)$ and RYGB (77.1 \pm 6.1$)$ - OAGB also achieved superior longterm remission of comorbidities, however, the trial has some methodological weaknesses. A new meta-analysis by Jia et al. concludes that OAGB results in a superior weight loss compared with RYGB, when an extended rather than standard length of the biliopancreatic limb is used (5).

The undisputed advantages of the OAGB over RYGB include its relative simplicity and less frequent intestinal obstructions. The disadvantage on the other hand is the greater likelihood of micronutrient deficiencies. Furthermore, there is still an ongoing discussion about the consequences of bile reflux and 
its potential role for promoting esophagogastric cancer. We recently published the first case of a cardia cancer 2 years after OAGB (6). This review explores the risk of cancer development after OAGB.

\section{Methods}

A narrative overview of the literature on postOAGB cancer and biliary reflux was performed using the MEDLINE database. We conducted a review of the English language literature by basing the search on the following keywords: "one-anastomosis gastric bypass" AND "biliary reflux", "single anastomosis bypass" AND "biliary reflux", "mini gastric bypass" AND "biliary reflux", "single anastomosis gastric bypass" AND "cancer", "one anastomosis bypass" and "cancer", "mini gastric bypass" AND "cancer".

\section{Gastric Cancer}

Our case was a 52-year-old man who underwent OAGB-MGB (biliopancreatic limb length $200 \mathrm{~cm}$ ) for super-obesity (BMI $52 \mathrm{~kg} / \mathrm{m}^{2}$ ) in January 2017 (6). Reflux symptoms had pre-existed. Grade C esophagitis had been documented at preoperative endoscopy, but no biopsies had been taken. Postoperative followup was regularly carried out with occasional reflux episodes under $40 \mathrm{mg}$ pantoprazole daily. When new-onset dysphagia for solid food led to a further endoscopy in February 2019 (BMI $32.2 \mathrm{~kg} / \mathrm{m}^{2}$ ), a non-obstructing circular adenocarcinoma at the gastroesophageal junction was discovered (AEG II, cT2NOM0) (Fig. 1). The Computer Tomography demonstrated a large hiatal hernia and the thickening of the esophagogastric junction (Fig. 2). After 3 cycles of a combination chemotherapy (FLOT), the radical abdomino-thoracic esophagectomy and 2 -field lymphadenectomy was successfully performed in July 2019. The gastric pouch was resected en-bloc with the left gastric artery and the remnant stomach served as the gastric conduit (Fig. 3). Histology revealed a complete pathological response. There were foci of Barrettmucosa without intraepithelial neoplasia and

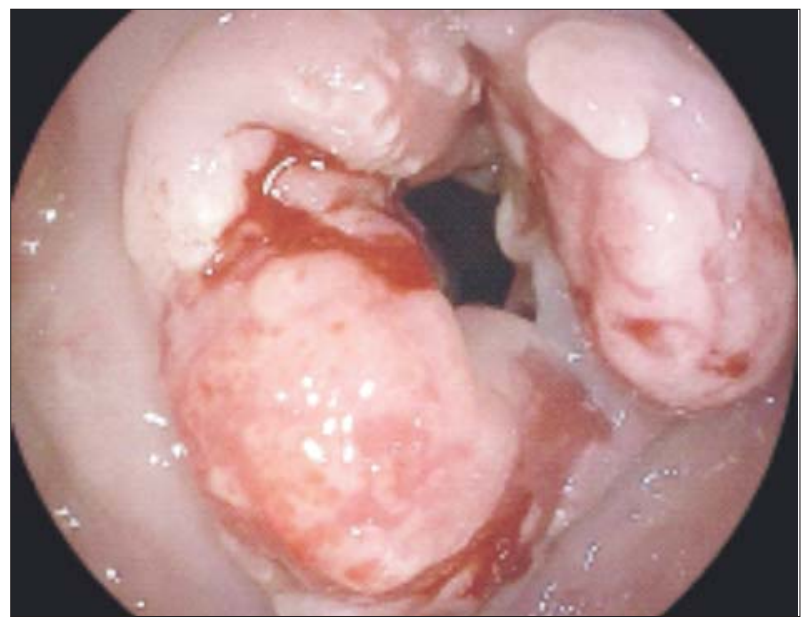

Figure 1. Endoscopy of the esophagogastric junction showing a small non-obstructing cancer

signs of reflux esophagitis. The gastric mucosa was negative for Helicobacter pylori.

By 2013, Scozzari et al. (7) had collected 13 post-bypass gastric cancers that had developed 2 months-29 years after RYGB (9 cases) and 4 cases after loop gastric bypass (an early version of OAGB). Three of these four carcinomas had developed in the excluded,

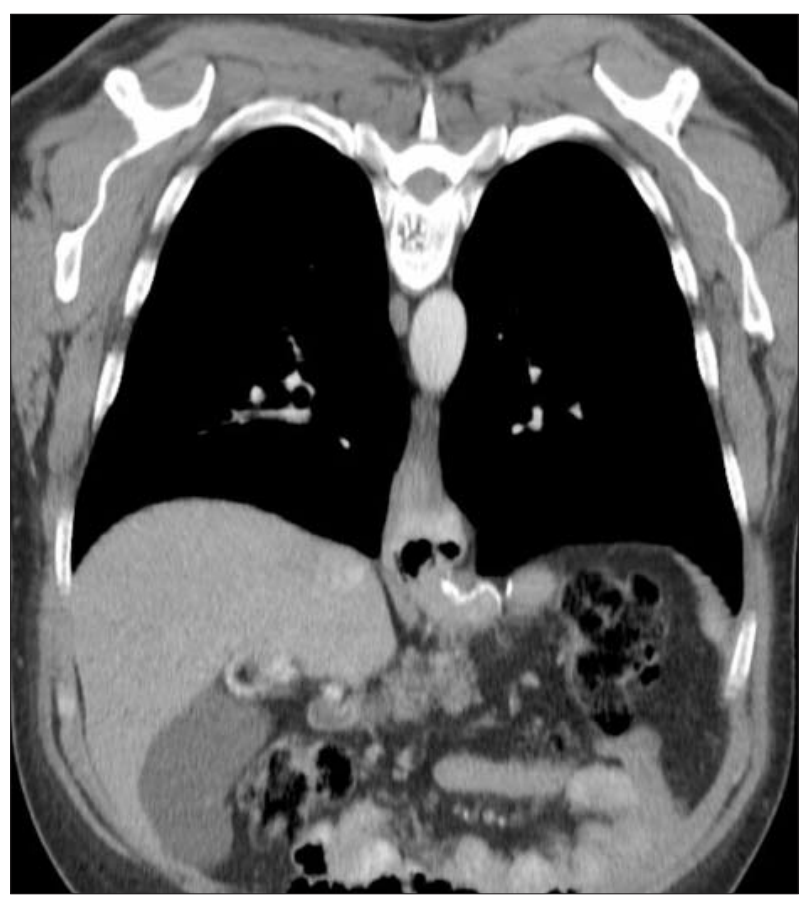

Figure 2. Paracoronary CT of the thorax demonstrating a large hiatal hernia with gastric pouch migration and thickening of the esophagogastric junction 


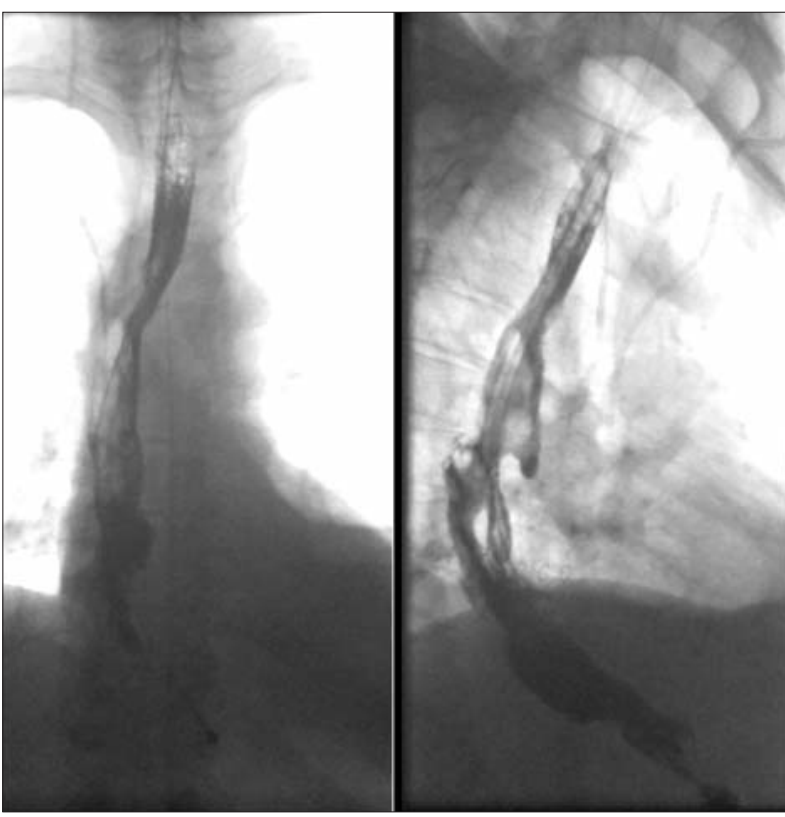

Figure 3. Postoperative gastrographin-swollow after abdominothoracic esophagectomy demonstrating an intact intrathoracic esophagogastrostomy. The remnant stomach was used as a gastric conduit

remnant stomach and one carcinoma in the gastric stump. Latter occurred as late as 26 years after bypass surgery. An updated review added another 12 cancer cases after RYGB: 8 esophageal carcinomas, one neoplasm located in the gastric pouch and three in the excluded stomach (8).

Gastric cancer after OAGB is exceedingly rare. One single case of a gastric cancer was included in the updated review (8): it developed in the remnant stomach 9 years after surgery (9). The Helicobacter pylori profile was not specified.

The observation of gastric cancer after partial gastrectomy is as old as it is controversial. Some European reports had suggested an increased risk of the development of stump carcinoma with time after gastric surgery for benign disease. The relative risk was 1.66 (95\% CL, 1.54-1.79) in a meta-analysis from 1990 (10). The risk of cancer in the gastric remnant occurred after a long latency of more than 15 years. But there were other studies at the same time period that failed to confirm this association: a total of 6459 patients were followed up for 25-33 years in a Swedish population-based cohort study.
Their gastric cancer rate was not different from that of sex- and age matched controls from the Swedish Cancer Registry (standardized incidence ratio $0.96 ; 95 \%$ confidence interval 0.78-1.16) (11). Data from Japan, which has one of the highest incidences of primary gastric cancer in the world, could also not find an increased cancer risk in the gastríc stump after partial gastrectomy for benign disease (12).

There are still surgeons who stick to the concept of the gastric stump as a risk factor for late gastric carcinoma. They explain this by a deleterious effect of chronic bile reflux into the stump after loop gastrojejunostomy (Billroth 2 operation) with subsequent inflammation and cellular proliferation. There are experimental data suggesting a carcinogenic impact of bile on gastric mucosa in rats but not in humans (13). Indeed, bile in the stomach is a common finding at upper GI-endoscopy even in asymptomatic healthy persons. Furthermore, after the thousands of vagotomy and pyloroplasty operations of the 1960-70s for duodenal ulcers (which permitted bile in the distal stomach), gastric cancer did not develop. Furthermore, the type of gastrectomy and the presence or absence of bile reflux do not affect the incidence of gastric stump carcinomas. The above cited meta-analysis found no significant difference between the risk after Billroth II (gastrojejunostomy) (RR 1.60; 85\% CL 1.152.18) and the risk after Billroth I (gastroduodenostomy) (RR 1.20; 95\% CL 1.01-1.42) $(\mathrm{p}=0.220)(10)$.

A randomized prospective study on 75 peptic ulcer patients compared the Billroth II-type to the Roux-en-Y-type reconstruction after antrectomy with selective vagotomy (14). Billroth II significantly increased the rates of intestinal metaplasia (24\% versus $3 \%$ ) and chronic atrophic gastritis (39\% versus 10\%) after a mean follow-up of 15 years, without development of an adenocarcinoma.

Large numbers of partial gastrectomies are still found in Asia. These operations are performed for early gastric cancer rather than benign disease. The incidence of gastric stump cancer is increased among these patients 
because of persisting risk factors such as chronic gastritis by Helicobacter pylori (15). Hosokawa et al. (16) reported that the cumulative risk of developing stump cancer after early gastric cancer was $2.4 \%$ at 5 years and $6.1 \%$ at 10 years. Similarly, Morgagni et al. (17) reported risks of $2.6 \%$ at 10 years, $3.2 \%$ at 15 years, and $4 \%$ at 20 years.

With the advent of effective medical therapies for peptic ulcer disease, the role of surgery rapidly declined and benign partial gastrectomies became extinct in the late $20^{\text {th }}$ century. Interestingly, the hypothesis of the operated stomach as a premalignant condition has prevailed since the times of peptic ulcer surgery - despite little or no evidence. The discussion has flared up again with the rise of OAGB, which in contrast to the RYGB allows bile and intestinal juice to freely reflux into the gastric pouch. Again, there is little or no evidence for an increased gastric cancer risk after loop gastrojejunostomy. The location of published true gastric cancer after OAGB and the old loop gastric bypass is interesting to note: 4 cases in the excluded remnant stomach and only one in the gastric stump. The number of cases is very low in relation to the many thousands of OAGBs constructed worldwide, although one could argue that only a relatively small number of patients have surpassed the latency period of 15-20 years yet.

\section{Esophageal Cancer}

Our reported post-OAGB cancer was a carcinoma of the gastric cardia but it belonged to the subgroup that behave more like esophageal (Barrett cancer, AEG I) than gastric adenocarcinomas. Another case of AEG I cancer after OAGB was very recently published by Aggarval et al. (18). A 52-year-old male underwent OAGB without prior endoscopy. Two years later, he developed progressive dysphagia, intermittent non-bilious vomiting and a sudden $19 \mathrm{~kg}$-weight loss. His endoscopy showed eccentric ulcerated growth in the lower esophagus extending to the gastrooesophageal junction and biopsy reported adenocarcinoma of oesophagus.

Gastroesophageal bile reflux was the likely cause of esophageal cancer in the two published cases including our own. Biliopancreatic reflux is directly responsible for esophageal adenocarcinoma in the animal model and in humans (19). Biliary reflux is the first (major) risk factor for the development of esophageal intestinal metaplasia in humans. Chronic biliary reflux can induce degeneration of Barrett metaplasia to adenocarcinoma. In patients with mixed reflux (acid and biliary), treatment of the acid component of the reflux with proton-pump inhibitors improves symptoms but does not provide a long-term protection from Barrett lesions. The biliary component of reflux by itself can induce a Barrett. The severity of esophagitis or Barrett lesions is related to the presence of a biliary component in the reflux. The duration of gastroesophageal mucosa exposure to the bile is a main determinant in the pathogenesis of degeneration. It is fair to assume that reflux had pre-existed before and persisted after bypass surgery in our own case. It is possible that OAGB accelerated malignant degeneration.

Current understanding and expert recommendations state that OAGB does not cause gastroesophageal reflux disease (2). Scintigraphically, bile fluxes into the distal but not up to the proximal gastric pouch (20), which is the main reason for constructing OAGB-pouches longer than $15 \mathrm{~cm}$ (21). Reviews confirm very low rates of symptomatic reflux into the esophagus $(22,23)$, however suspicions of underestimation and underreporting have been raised with a call for higher clinical attention (24). There is no systematic prospective evaluation regarding this matter. A reason why reflux symptom might be rare is that gastric acid and bile can neutralize. The prevalence of asymptomatic gastroesophageal reflux after OAGB is unknown.

Gastroesophageal investigational studies have produced conflicting data. Tolone et al. (25), for example, re-examined 15 patients without preoperative gastroesopageal symptoms one year after OAGB with manometry 
and 24-hour pH-impedance monitoring. The gastroesophageal pressure gradient dropped from 10.3 to $6.4(p<0.01)$. OAGB did not compromise the gastroesophageal junction function and did not increase gastroesophageal reflux. In contrast, Doulamie et al. (26) prospectively investigated 11 patients after OAGB and found that the DeMeester score (40.48 versus 24.16, $\mathrm{p}=0.339$ ) had an increasing trend 12 months after surgery. Acid reflux episodes decreased, whereas non-acid reflux episodes increased postoperatively, both in proximal and distal esophagus. Total median bolus clearance time and acid clearance time increased. De novo GERD developed in 2 patients $(28.6 \%)$ and worsening of already existing GERD developed in all patients with preoperative evidence of GERD.

\section{Conclusions}

What are the clinical consequences? The fear of gastric cancer after OAGB seems to be unfounded and no specific surveillance is needed. Epigastric symptoms, however, should prompt an endoscopic investigation. The fear of esophageal cancer after OAGB is founded when gastroesophageal reflux and or hiatal hernia existed prior to the bypass or developed de novo after the surgery. Therefore, gastroscopy before bypass should be mandatory. It is our opinion, that GERD and/or a significant hiatal hernia are best treated with a RYGB rather than an OAGB, however, others recommend differently. Rutledge (21) proposes the no-touch principle of hernias with the exception of large ones, whilst Cabajo (27) simultaneously explores the hiatus and repairs a hernia when constructing an OAGB. Simultaneous hiatoplasty with OAGBMGB was not recommended in a 2018 Delphistructured consensus amongst an international group of "MGB-experts" (2). The concept on which this decision was based was the antireflux property of the OAGB as the result of the low pressure inside the gastric pouch. The pre-existence of a hiatal hernia up to $4 \mathrm{~cm}$ and mild reflux disease was not considered a contraindication for OAGB. However, such a consensus was not reached for larger and highly symptomatic hernias.

In cases of symptomatic reflux after OAGB, diversion into a Roux-en-Y construction should be recommended. RYGB is an antireflux procedure which induces regression of Barrett metaplasia and thus, prevents rather than promotes esophageal cancer (28). In cases of asymptomatic reflux, an endoscopic screening appears adequate for us with intervals of less than two years.

\section{Conflict of Interest}

The authors declare no conflicts of interests.

\section{References}

1. Rutledge R. The mini-gastric bypass: experience with the first 1,274 cases. Obes Surg. 2001;11(3):276-80.

2. Mahawar KK, Himpens J, Shikora SA, Chevallier JM, Lakdawala M, De Luca $\mathrm{M}$, et al. The First Consensus Statement on One Anastomosis/Mini Gastric Bypass (OAGB/MGB) Using Modified Delphi Approach. Obes Surg. 2018:28(2):303-312.

3. Robert M, Espalieu P, Pelascini E, Caiazzo R, Sterkers A, Khamphommala $L$, et al. Efficacy and safety of one anastomosis gastric bypass versus Roux-en-Y gastric bypass for obesity (YOMEGA): a multicentre, randomised, open-label, non-inferiority trial. Lancet. 2019;393(10178):1299-309.

4. Ruiz-Tovar J, Carbajo MA, Jimenez JM, Jose Castro M, Gonzalez G, Ortiz-de-Solorzano $\mathrm{J}$ et al. Long-term follow-up after sleeve gastrectomy versus Roux-en-Y gastric bypass versus one-anastomosis gastric bypass: a prospective randomized comparative study of weight loss and remission of comorbidities. Surg Endosc. 2019;33(2):401-10.

5. Jia D, Tan H, Faramand A, Fang F. One Anastomosis Gastric Bypass Versus RouX-en-Y Gastric Bypass for Obesity: a Systematic Review and Meta-Analysis of Randomized Clinical Trials. Obes Surg. 2019 Nov 20. [Epub ahead of print]

6. Runkel $M$, Pauthner $M$, Runkel N. The First Case Report of a Carcinoma of theGastric Cardia (AEG II) After OAGB-MGB. Obes Surg. 2019 Oct 31 [Epub ahead of print]

7. Scozzari G, Trapani R, Toppino M, Morino M. Esophagogastric cancer after bariatric surgery: systematic review of the literature. Surg Obes Relat Dis. 2013;9(1):133-42.

8. Musella M, Berardi G, Bocchetti A, Green R, Cantoni V, Velotti N, et al. Esophagogastric Neoplasms Following Bariatric Surgery: an Updated Systematic Review. Obes Surg. 2019;29(8):2660-2669.

9. Wu CC, Lee WJ, Ser KH, Chen JC, Tsou JJ, Chen SC, et al. Gastric cancer after mini-gastric bypass surgery: a case report and literature review. Asian J Endosc Surg. 2013;6(4):303-6.

10. Tersmette AC, Offerhaus GJ, Tersmette KW, Giardiello FM, Moore GW, Tytgat GN, et al. Meta-analysis of the risk of gastric stump cancer: detection of high risk patient subsets for stomach cancer after remote partial gastrectomy for benign conditions. Cancer Res. 1990:50(20):6486-9.

11. Lundegțdh G, Adami HO, Helmick C, Zack M. Risk of cancer following partial gastrectomy for benign ulcer disease. Br J Surg. 1994:81(8):1164-7

12. Tokudome S, Kono S, Ikeda M, Kuratsune M, Sano C, Inokuchi K, et al. A prospective study on primary gastric stump cancer 
following partial gastrectomy for benign gastroduodenal diseases Cancer Res. 1984;44:2208-2212.

13. Kondo K. Duodenogastric reflux and gastric stump carcinoma. Gastric Cancer. 2002;5(1):16-22.

14. Csendes A, Burgos AM, Smok G, Burdiles P, Braghetto I, Díaz JC Latest results 12-21 years) of a prospective randomized study comparing Billroth II and Roux-en-Y anastomosis after a partial gastrectomy plus vagotomy in patients with duodenal ulcers. Ann Surg. 2009;249(2):189-94.

15. Ohira M, Toyokawa T, Sakurai K, Kubo N, Tanaka H, Muguruma K, et al. Current status in remnant gastric cancer after distal gastrectomy. World J Gastroenterol. 2016;22(8):2424-33.

16. Hosokawa O, Kaizaki Y, Watanabe K, Hattori M, Douden K, Hayashi $\mathrm{H}$, et al. Endoscopic surveillance for gastric remnant cancer after early cancer surgery. Endoscopy. 2002;34:469-473.

17. Morgagni P, Gardini A, Marrelli D, Vittimberga G, Marchet A, de Manzoni G, et al. Gastric stump carcinoma after distal subtota gastrectomy for early gastric cancer: experience of 541 patients with long-term follow-up. Am J Surg. 2015;209:1063-1068.

18. Aggarwal S, Bhambri A, Singla V, Dash NR, Sharma A Adenocarcinoma of oesophagus involving gastro-oesophageal junction following mini-gastric bypass/one anastomosis gastric bypass. J Minim Access Surg. 2019 Feb 18. J Minim Access Surg. 2019 Feb 18. doi: 0.4103/jmas.JMAS_320_18. [Epub ahead of print]

19. Greene CL, Worrell SG, DeMeester TR. Rat reflux model of esophageal cancer and its implication in human disease. Ann Surg. 2015;262:910-24.

20. Saarinen T, Räsänen J, Salo J, Loimaala A, Pitkonen M, Leivonen
M, et al. Bile Reflux Scintigraphy After Mini-Gastric Bypass. Obes Surg. 2017;27(8):2083-2089.

21. Deitel M, Rutledge R. Mini-gastric bypass: Prevention and management of complications in performance and follow-up. Int $\mathrm{J}$ Surg. 2019;71:119-123.

22. Parmar CD, Mahawar KK. One Anastomosis (Mini) Gastric Bypass Is Now an Established Bariatric Procedure: a Systematic Review of 12,807 Patients. Obes Surg. 2018:28(9):2956-2967.

23. Wang FG, Yan WM, Yan M, Song MM. Outcomes of Mini vs Rouxen- $Y$ gastric bypass: A meta-analysis and systematic review. Int $\mathrm{J}$ Surg. 2018;56:7-14

24. Runkel N. The Gastric Migration Crisis in Obesity Surgery. Obes Surg. 2019;29(7):2301-2302.

25. Tolone S, Cristiano S, Savarino E, Saverio Lucido F, Fico DI, Docimo L. Effects of omega-loop bypass on esophagogastric junction function. Surg Obes Relat Dis. 2016;12(1):62-9.

26. Doulami G, Triantafyllou S, Albanopoulos K, Natoudi M, Zografos G. Theodorou D. Acid and nonacid gastroesophageal reflux after single anastomosis gastric bypass. An objective assessment using 24-hour multichannel intraluminal impedance-pH metry. Surg Obes Relat Dis. 2018;14(4):484-488.

27. Carbajo MA, Luque-de-León E, Jiménez JM, Ortiz-de-Solórzano J, Pérez-Miranda M, Castro-Alija MJ. Laparoscopic one-anastomosis gastric bypass: technique, results, and long-term follow-up in 1200 patients. Obes Surg. 2017;27(5):1153-67.

28. Felsenreich DM, Langer FB, Bichler C, Eilenberg M, Jedamzik J, Kristo I, et al. Roux-en-Y Gastric Bypass as a Treatment for Barrett's Esophagus after Sleeve Gastrectomy. Obes Surg. 2019 Dec 5. [Epub ahead of print] 